\title{
Omega-3-Fatty Acids: Cardiovascular Disease
}

\author{
Gundu Rao HR* \\ Emeritus Professor of Laboratory Medicine and Pathology, University of Minnesota, USA
}

Submission: April 27, 2018; Published: May 25, 2018

*Corresponding author: Gundu Rao HR, Emeritus Professor, Laboratory Medicine and Pathology, Director, Thrombosis Research, Lillehei Heart Institute, University of Minnesota, 12500 Park Potomac Ave, Unit 306N, Potomac MD 20854, USA, Tel: 301444 4545; Email: gundurao9@gmail.com

\section{Introduction}

Possible health benefits of dietary fish, fish fats, fish oil, including cod liver oil, is known in the scientific community for over a hundred years. Studies by Dyerberg \& Bang [1] on a small group of Eskimos ignited the research interest in the scientific community on this line of approach to the management of cardiovascular diseases. Since that time, results of many original studies have been published on the role of prostaglandins in health and disease [2-14]. Based on the results of such studies use of dietary omega-3 fatty acids have been recommended for the management of risks for cardiovascular disease as well as anti-inflammatory agents. Food and Drug administration has approved icosapent ethyl (Vascepa-Amarin), which contains mostly eicosapentaenoic acid (EPA, 96\%) for the management of high triglycerides in the circulating blood. In spite of several basic, applied and clinical studies on the benefits of omega- 3 fatty acids, the subject has become quite controversial. In this mini review, we will discuss briefly role of prostaglandins in cardiovascular physiology, some of the controversies, expectations and limitations of omega-3 fatty acids as therapeutic agents.

Half a century has passed since Dyerberg \& Bang [1] published their seminal work on hemostatic function and platelet fatty acids in Eskimos. The very first sentence of their abstract says, "Death from cardiovascular disease is rare among Eskimos". They attributed this to the dietary habits of Eskimos, which included fish-rich in omega-3 polyunsaturated fatty acids (PUFA). In their studies, they found that the Eskimos had longer bleeding-time due to a reduction in platelet aggregation. They also speculated that C20:5 omega 3 fatty acids in this population are converted in their vessel wall tissue to an anti-aggregatory prostacyclin $\left(\mathrm{PGI}_{3}\right)$. In view of these observations they concluded that dietary substitution of arachidonic acid by Eicosapentaenoic acid might reduce incidence of thrombotic disorders including myocardial infarction [1]. Since this discovery, numerous research papers and reviews have been written on this subject, specifically in relation to platelet function $[2,3]$. Since two pharmacologically opposing bioactive molecules (thromboxane; $\mathrm{TXA}_{2}$ and prostacyclin; $\mathrm{PGI}_{2}$ ) are generated by Arachidonic acid (AA) metabolism, we will briefly describe arachidonic acid metabolism and the role of AA metabolites in modulating platelet function.

Arachidonic acid is a 20-carbon polyunsaturated fatty acid (20:46) found in membrane phospholipids. Agonist-mediated activation mechanisms stimulate Phospholipase $A_{2}$, which facilitates the release of arachidonic acid from phospholipids. $\mathrm{AA}$ is converted to prostaglandin (PG) endoperoxides $\left(\mathrm{PGG}_{2} /\right.$ $\mathrm{PGH}_{2}$ ) by cyclooxygenase (Prostaglandin $\mathrm{G} / \mathrm{H}$ synthase; COX1). These transient metabolites are converted by thromboxane synthetase to thromboxane $A_{2}$, which is the major metabolite of this pathway in platelets. Whereas, in vascular tissues, the endoperoxides generated by COX-1 enzymes are transformed by prostacyclin synthetase to prostacyclin $\left(\mathrm{PGI}_{2}\right)$. Thromboxane is a potent platelet agonist and a vasoconstrictor. Prostacyclin is an antiplatelet compound and exerts vasodilatory effects on vascular tissues. Thus from a single substrate AA, two pharmacologically opposing vasoactive prostanoids are generated by platelets and vascular tissues. Aspirin selectively acetylates the hydroxyl groups of a single serine residue (position 529) in the prostaglandin $\mathrm{G} / \mathrm{H}$ synthase and causes irreversible inhibition of the activity of this enzyme. Inhibition of PG synthase results in the decreased conversion of $\mathrm{AA}$ to $\mathrm{PG}$ endoperoxides, $\mathrm{PGG}_{2} / \mathrm{PGH}_{2}$. Molecular mechanisms involved in aspirin-mediated inhibition of prostaglandin G/H synthase are well documented [4].

Prostaglandins are produced by the action of enzymes on essential fatty acids. There are two major pathways, one that uses the double unsaturated omega- 6 linoleic acid and the other with triple-unsaturated omega- 3 alpha-lionenic acid. In the omega- 6 pathway, the series- 1 prostaglandins are produced from a 20-carbon, triple unsaturated fatty acid (dihomo--linoleic acid). The series 2(diene) prostaglandins are produced from 20-carbon quadruple saturated fatty acid called arachidonic acid. The omega-3 pathway, the series 3 (triene) prostaglandins are produced from a 20 -carbon quintuple unsaturated fatty acid called eicosapentaenoic acid (EPA) found in abundance in fish liver oils. In brief, the series 2 prostaglandins seem to be involved in swelling, inflammation, clotting and vasodilation, while the 
series-1 seems to exert the opposite effect. The observed low incidence of CAD in Greenland Eskimos seems to be attributed to reduced platelet aggregability. Platelets-rich in EPA seems to produce prostaglandins of the three series $\left(\mathrm{TXA}_{3}\right)$, which are weakly aggregatory. On the other hand, vessel wall uses this substrate to produce prostacyclin of the three series $\left(\mathrm{PGI}_{3}\right)$, with normal vasodilatory properties. Similarly, it was believed that the prostaglandins of the 4 series (tetraenes; TXA4, PGI4) were generated by Docosahexaenoic acid (DHA).

Studies from our laboratory at the University of Minnesota as well as that of others demonstrated that DHA is a strong inhibitor of prostaglandin synthesis as well as platelet function $[12,13]$. DHA is a potent competitive inhibitor of arachidonic acid metabolism by sheep vesicular gland prostaglandin synthetase. Based on our in vitro studies we concluded that these fatty acids (EPA,20:5-3 and DHA, 20:6-3) if released in the vicinity of the enzymes (COX) could compete with arachidonic acid for the heme site of the enzyme and prevent the conversion of AA to series-2 prostaglandins $\left(\mathrm{TXA}_{2}\right.$ and $\mathrm{PGI}_{2}$ ) [15]. Murthy [16], Endocrinologist, Hennepin County Medical Center, Minneapolis, did a double-blind study with $12 \mathrm{~g}$ of fax oil containing $55 \%$ of alpha linolenic acid, a precursor of EPA (20:5-3) and DHA (22:6-3) and found no significant prolongation of bleeding times. EPA and DHA levels in the platelet were although detectable, very low and nowhere near to what Dyerberg [1] found in the Eskimos [16]. We at the University of Minnesota studied oral dose of EPA (EPA300Mg/ DHA130Mg; Shaklee Products) two capsules a day for 60 days or 15 capsules a day for three days. We found no significant effect on agonist induced irreversible aggregation of platelets. Based on the results of our in vitro and in vivo studies, we and others concluded that in platelets, preferred substrate for prostaglandin synthesis is arachidonic acid and chances of producing large quantities of 3 series $\left(\mathrm{TXA}_{3}\right)$ or 4 series $\left(\mathrm{TXA}_{4}\right)$ of prostaglandins was very limited [15-17].

The fact that the seminal article by Dyerberg \& Bang [1] claimed that Eskimos do not die of cardiovascular disease and the assumption that their fish diet is protecting them, raised the expectations of patients, clinicians as well as public at large. In view of the fact that fish diet may pose some toxicity (PCB and mercury contamination) problems, public health professional developed guidelines as to how much fish one can consume per week or month to be safe. Furthermore, not all fish is rich in omega-3 fatty acids. Therefore, pharmaceutical industries started marketing a variety of fish oil supplements. Now coming back to controversies, although manufacturers use terms like medical grade, pharmaceutical grade to imply purity and potency of their preparations, as supplements these claims are not regulated. Formulations exist of variable ratios of EPA/DHA and optimal ratio of these combinations for heart disease prevention is not yet determined.

April issue of JAMA in its medical News and Perspectives describes recent findings on fish oil supplementation as, "Another
Nail in the Coffin for Fish Oil Supplements" [18]. The article concluded that popular fish oil capsules do little to protect patients with heart disease. The findings of 10 clinical trials are at odds with the advice from the American Heart Association (AHA), including a 2017 science advisory recommendation to consider fish oil supplementation for patients with a recent myocardial infarction or heart attack. Under the heading, "Original Investigation" a recent article in JAMA cardiology asked a very important question which is on everyone's mind? [19]. Does supplementation with marine-derived omega-3 fatty acids have any association with reduction in fatal or non-fatal coronary artery disease in people at high risk of cardiovascular disease? This meta-analysis of 10 clinical trials involving 77917 participants demonstrated that supplementation with marine-derived omega-3 fatty acids for a mean 4.4 years had no significant association with reduction in fatal or nonfatal coronary heart disease or any major vascular events. In this review we have barely touched the topic, we urge the readers to refer to the reports of these clinical trials for further information [20-29].

In spite of all said and done, the acute vascular events resulting with a heart attack or stroke are mediated by hyperactive platelets or prothrombotic coagulation state. As mentioned in an earlier paragraph, our in vivo studies did not show any inhibitory effect of omega-3 fatty acids on platelet function. There is some controversy about the absorption and incorporation of EPA and DHA into plasma lipids, depending upon whether they are used as ethyl ester (EE) or in a triglyceride (TG) formula. Based on a randomized double-blind study on the effects of such derivatives, it can be concluded that fish oil derivatives of both the forms are well incorporated into plasma lipids and exert similar influence on platelet function [30]. Results from another study on blood clotting parameters and in vitro platelet aggregation, suggests that adding $6 \mathrm{~g} / \mathrm{d}$ of dietary DHA for 90 days to a typical western diet containing less than $50 \mathrm{mg} / \mathrm{d}$ of DHA produces no observable physiological changes in blood coagulation, platelet function or thrombotic tendencies in healthy adult males [31]. In view of these observations, we feel that dietary supplementations with omega-3 fatty acids may not have significant inhibitory activity on platelet function as well as coagulation pathways.

In conclusion, the discovery by Dyerberg \& Bang [1] that Eskimos had lower incidence of cardiovascular disease and increased bleeding tendencies, suggested a role for fish diet in the modulation of platelet and coagulation functions, which by and large are responsible for acute vascular events. Further studies speculated that the omega-3 fatty (EPA 20:53) acids if incorporated into the platelet lipids upon release would produce prostaglandins of the 3 series $\left(\mathrm{TXA}_{3}\right)$ and $\mathrm{PGI}_{3}$. These studies demonstrated that $\mathrm{TXA}_{3}$ was less potent agonist whereas PGI3 as equally potent vasodilator and a platelet antagonist. However, studies from our laboratory showed that arachidonic acid is the preferred substrate for the generation of series 2 prostanoids $\left(\mathrm{TXA}_{2}, \mathrm{PGI}_{2}\right)$. After half a century of work and over ten major clinical trials, there seems to be an agreement in the scientific 
community that dietary omega-3 fatty acids do not lower the incidence of cardiovascular risks. However, we do not know whether consumption of marine fish has a very different effect on cardiovascular physiology and function.

The American heart association recommends 2 to $4 \mathrm{~g}$ of EPA plus DHA per day as capsules under a physician 's care, for patients who need to lower their triglyceride level. In an excellent review on the subject, the authors concluded that a well-designed randomized clinical trial will be important to determine the extent to which triglyceride and HDL-C lowering through supplementation with marine-derived omega 3 PUFA improves outcomes beyond standard-care therapy [32]. Omega-3 PUFA is also recommended as an anti-inflammatory drug by clinicians. Dietary supplements lack specificity in terms of their pharmacological efficacy. On the other hand, a well-formulated therapeutic drug can provide significant beneficial effects. Paul Ridker, Director of the Center for Cardiovascular Disease Prevention at Brigham and Women's Hospital, at Boston, USA says that "For the first time we have been able to definitely show that lowering inflammation independent of cholesterol reduces cardiovascular risk. The study was conducted with over 10,000 patients, who had previously heart attack and had persistently high levels of C-reactive protein (hsCRP), a marker of inflammation. The drug tested was Canakinumab a monoclonal antibody that neutralizes interleukin 1 signaling, thereby suppressing inflammation [33]. Hypothesis for this approach was developed based on the fact that of the patients on high statin therapy, there were still a significant proportion of those who still had increased hsCRP.

A growing body of research indicates that consuming fish and other types of seafood may be good for heart health. However, as indicated in the large number of clinical studies the beneficial effects of Omega-3 PUFA supplements on cardiovascular endpoints or outcomes are unclear and might vary widely based on the use of other cardioprotective agents, the types and the source of Omega-3 PUFA. Understanding the mechanisms underlying a disease and disease processes will help us develop better and efficient drug therapy for the management of chronic metabolic diseases. As for as the role of dietary supplements and complimentary therapies in the management of cardiovascular disease, in my opinion, they have a very important role in the preventive strategies, and this will be the subject of my next mini review.

\section{References}

1. Dyerberg, Bang HO (1979) Hemostatic function and platelet polyunsaturated fatty acids in Eskimos. Lancet 2(8140): 433-435.

2. Goodnight SH (1988) Effects of dietary fish oil and omega-3 fatty acids on platelets and blood vessels. Semin Thromb Hemost 14(3): 285-289.

3. Mueller BA, Talbert RL (1993) Biological mechanisms and cardiovascular effects of omega-3 fatty acids. Clin Pharmacy $7(11)$ : 795-807.

4. Willis AL (1987) The eicosanoids: An introduction and an overview. In: Willis AL (Ed.), Handbook of Eicosanoids: Prostaglandins and lipids. Boca Raton, USA.
5. Needleman P, Turk J, Jackschik BA, Morrison AR, Lefkovith JB (1986) Arachidonic acid metabolism. Annual Review of Biochemistry 55: 69102.

6. Lands WEM, Samuelsson B (1968) Phospholipid precursors of prostaglandins. Biochim Biophs Acta 164(2): 426-429.

7. Moncada S, Vane JR (1979) Arachidonic acid metabolites and the interactions between platelets and blood-vessel walls. N Engl J Med 300(20): 1142-1147.

8. Needleman P, Minkes M, Raz A (1976) Thromboxanes: selective biosynthesis and distinct biological properties. Science 193(4248): 163-165.

9. Whitaker MO, Wyche A Fitzpatrick F, Sprecher H, Needleman P (1979) Triene prostaglandins: Prostaglandin $\mathrm{D}_{3}$ and Eicosapentaenoic acid as potent antithrombotic substances. PNAS 76(11): 5919-5923.

10. Dyerberg J, Jorgenson KA, Arnfield T (1980) Human umbilical blood vessel converts all cis-5,8,11,17-eicosapentaencoic acid to prostaglandin $\mathrm{I}_{3}$. Prostaglandins 22(6): 589-593.

11. Fisher S, Weber PC (1983) Thromboxane $A_{3}\left(T_{X A}\right)$ is formed in human platelets after dietary eicosapentaenoic acid (C20: 5w3). Biochem Biophys Res Commun 116(3): 1091-1099.

12. Rao GHR, Radha E, White JG (1983) Effect of Docosahexaenoic acid (DHA) on arachidonic acid metabolism and function. Biochem Biophs Res Commun 117(2): 549-555.

13. Corey EJ, Shih C, Cashman JR (1983) Docosahexaenoic acid is a strong inhibitor of prostaglandin but not leukotriene synthesis. Proc Natl Acad Sci USA 80(12): 3581-3584.

14. Lands WEM (1992) Biochemistry and physiology of n-3 fatty acid. FASEB J 6(8): 2530-2536.

15. Rao GHR, White JG (1985) Heme-polyenoic acid interaction and prostaglandin synthesis. In: Prostaglandins, Leukotrienes, and Lipoxins, Plenum Publishing Co, New York, USA, pp. 34-69.

16. Murthy M (1999) Polyenoic acids and platelet function. In: Gundu Rao HR (Ed.), Handbook of platelet physiology and pharmacology. Kluwer Academic Publishers, Boston, USA, pp. 269-292.

17. Rao GHR, Kishore NP, Peller JD, White JG (1987) Influence of polyenoic acids on arachidonic acid metabolism and platelet function. In: LL Gallo (Ed.), Cardiovascular disease. Plenum Press, New York, USA, pp. 495-505.

18. Abbasi J (2018) Another nail in the coffin for fish oil supplements. JAMA.

19. Aung T, Hesley J, Kromhout D (2018) Association of Omega-3 fatty acid supplement use with cardiovascular disease risks. JAMA Cardiol 3(3): 225-234.

20. GISSI-Prevenzione Investigators (1999) Dietary supplementation with n-3 polyunsaturated fatty acids and vitamin E after myocardial infarction: results of the GISSI-Prevenzione trial. Lancet 354(9177): 447-455.

21. Tavazzi L, Maggioni AP, Marchioli R, Gissi-HF Investigators (2008) Effect of $n-3$ polyunsaturated fatty acids in patients with chronic heart failure (the GISSI-HF trial): a randomised, double-blind, placebocontrolled trial. Lancet 372(9645): 1223-1230.

22. Kromhout D, Giltay EJ, Geleijnse JM, Alpha Omega Trial Group (2010) N-3 fatty acids and cardiovascular events after myocardial infarction. N Engl J Med 363(21): 2015-2026.

23. Einvik G, Klemsdal TO, Sandvik L, Hjerkinn EM (2010) A randomized clinical trial on N-3 polyunsaturated fatty acids supplementation and all-cause mortality in elderly men at high cardiovascular risk. Eur J Cardiovasc Prev Rehabil 17(5): 588-592. 
24. Bosch J, Gerstein HC, Dagenais GR, Origin Trial Investigators (2012) N-3 fatty acids and cardiovascular outcomes in patients with dysglycemia. N Engl J Med 367(4): 309-318.

25. Rauch B, Schiele R, Schneider S, OMEGA Study Group (2010) OMEGA, a randomized, placebo-controlled trial to test the effect of highly purified omega-3 fatty acids on top of modern guideline-adjusted therapy after myocardial infarction. Circulation 122(21): 2152-2159.

26. Galan P, Kesse-Guyot E, Czernichow S, Briancon S, Blacher J, et al. (2010) Effects of B vitamins and omega 3 fatty acids on cardiovascular diseases: a randomised placebo controlled trial. BMJ 341: c6273.

27. Risk and Prevention Study Collaborative Group (2013) N-3 fatty acids in patients with multiple cardiovascular risk factors. N Engl J Med 368(19): 1800-1808.

28. Yokoyama M, Origasa H, Matsuzaki M, Japan EPA lipid intervention study (JELIS) Investigators (2007) Effects of eicosapentaenoic acid on major coronary events in hypercholesterolaemic patients (JELIS): a randomised open-label, blinded endpoint analysis. Lancet 369(9567) 1090-1098
29. Bonds DE, Harrington M, Worrall BB, Writing Group for the AREDS2 Research Group (2014) Effect of long-chain $\omega-3$ fatty acids and lutein+zeaxanthin supplements on cardiovascular outcomes: results of the Age-Related Eye Disease Study 2 (AREDS2) randomized clinical trial. JAMA Intern Med 174(5): 763-771.

30. Hansen JB, Olsen JO, Wilsgard L (1993) Comparative effects of prolonged intake of highly purified fish oils as ethyl ester or triglyceride on lipids, hemostasis, and platelet function in normolipaemic men. Eur J Clin Nutri 47(7): 497-507.

31. Nelson GJ, Schmidt PS, Bartolini GL (1997) The effect of dietary docosahexaenoic acid on platelet function, platelet fatty acid composition, and blood coagulation in humans. Lipids 32(11): 1129 1136.

32. Miller M, Stone NJ, Ballantyne C (2011) Triglycerides and cardiovascular disease. Circulation 123: 2292-2333.

33. Ridker PM, Everett BM, Thuren T (2017) Anti-inflammatory therapy with Canakinumab for atherosclerotic disease. N Engl J Med 377(12) 1119-1131.

\begin{tabular}{l} 
Your next submission with Juniper Publishers \\
will reach you the below assets \\
- Quality Editorial service \\
- Swift Peer Review \\
- Reprints availability \\
- E-prints Service \\
- Manuscript Podcast for convenient understanding \\
- Global attainment for your research \\
- Manuscript accessibility in different formats \\
( Pdf, E-pub, Full Text, Audio) \\
- Unceasing customer service \\
Track the below URL for one-step submission \\
https://juniperpublishers.com/online-submission.php \\
\hline
\end{tabular}

